\title{
Diabetic and hypoglycemic neuropathy - a comparison in the BB rat
}

\author{
Anders A.F. Sima, Wei-Xian Zhang* and Douglas A. Greene ${ }^{1}$ \\ Neuropathology Research Laboratory. Department of Pathology, University of Manitoba, Winnipeg, MB, Canada, and 'Diabetes \\ Research and Training Center. University of Michigan. Ann Arbor, MI, U.S.A.
}

(Received 25 October 1988, accepted 1 December 1988)

Key words: Diabetes; Hypoglycemia; Insulin; Peripheral neuropathy; BB rat

\section{Summary}

Functional and structural neuropathy was examined in hyperglycemic (diabetic) BB rats maintained on small maintenance doses of insulin, hyperglycemic BB rats receiving no insulin, and BB rats in whom hypoglycemia was induced by the administration of excessive insulin doses. The data were compared with those of nondiabetic age- and sex-matched BB rats. Functional deficits and structural abnormalities were comparable in diabetic rats with and without insulin supplementation, suggesting that the generally necessary insulin dosing in this model does not per se account for the neuropathy. Hypoglycemic neuropathy was characterized by slowing of nerve conduction velocity, marked loss of anterior horn motoneurons and Wallerian degeneration, as well as loss of large myelinated fibers, suggesting a neuropathy involving predominantly motoneurons. Diabetic neuropathy was not associated with nerve cell loss but showed marked axonal atrophy involving predominantly sensory fibers. Thus, diabetic and hypoglycemic neuropathies are two distinguishable entities under strict experimental conditions, but may overlap in human diabetic subjects in whom tight insulin control is desirable.

Address for correspondence: Dr. Anders A.F. Sima, Neuropathology Research Laboratory, Department of Pathology. University of Manitoba, 770 Bannatyne Avenue, Winnipeg, MB, R3E OW3, Canada.

*Dr. Zhang is a visiting scientist from the Medical University of Shanghai, Peoples Republic of China, supported by ICI-Americas, Wilmington. DE. U.S.A.

\section{Introduction}

Diabetic neuropathy in human subjects is associated with impaired nerve conduction velocity and a spectrum of structural changes that include axonal degeneration, paranodal demyelination and loss of 
myelinated nerve fibers, as well as endoneurial ischemic damage [1-9].

The spontaneously diabetic BB rat is an authentic model of human insulin-dependent diabctes mellitus (IDDM) and as such develops the whole spectrum of functional and structural changes seen in human diabetic neuropathy including nerve fiber loss and endoneurial ischemic lesions. We have previously used this model extensively to investigate the nature of underlying metabolic and functional abnormalities in diabetic peripheral nerve and to correlate these changes with the development of subsequent structural abnormalities [10-20]. In brief, these studies have suggested that the initial metabolic defect. involving an activated polyol pathway, decreased myo-inositol content and impaired activity of ( $\mathrm{Na}, \mathrm{K})$-ATPase, via a protein kinase $\mathrm{C}$ defect, is a consequence of hyperglycemia, and precedes and conditions the development of structural diabetic neuropathy $[10,2123]$. The nerve conduction slowing in the $\mathrm{BB}$ rat has been attributed to alterations in nerve $\mathrm{Na}$ and $\mathrm{Na}$-related metabolism, secondary to impaired ( $\mathrm{Na}, \mathrm{K}$ )-ATPase activity, resulting in a selective nerve conduction block of large and rapidly conducting myelinated nerve fibers [11-13]. Accompanying histologically demonstrated paranodal nerve fiber swelling has been associated with a fivefold elevation of intraaxonal $\mathrm{Na}$ concentration [12]. These metabolic. electrophysiological and structural abnormalities are completely reversed by vigorous insulin treatment within the first 6 weeks of diabetes [10.13].

A countervailing opinion, however, holds that the degeneration of peripheral nerve seen in the diabetic BB rat may be a complication of insulin treatment rather than a manifestation of diabetes $[24,25]$, since the diabetic BB rat generally requires small daily maintenance doses of insulin for its survival $[26,27]$. However, a small percentage of diabetic BB rats can be maintained at substantial hyperglycemic levels for prolonged periods of time without exogenous insulin supplementation, probably due to an incomplete immune-mediated destruction of insulin secreting $\beta$ cells $[26,27]$.

To assess the role of even small doses of exog- enous insulin in the development of diabetic polyneuropathy in the BB rat, we compared functional and structural peripheral nerve abnormalities in diabetic BB rats receiving small daily insulin injections, and those maintained at identical hyperglycemic levels without exogenous insulin supplementation. The nerve conduction and morphometric data obtained from these two diabetic groups were compared with those obtained from BB rats rendered hypoglycemic following excessive exogenous insulin administration, since previously reported abnormalities in insulin-treated diabetic rats $[24,25]$ could represent hypoglycemic nerve damage.

\section{Material and methods}

\section{Animals}

Prediabetic male BB rats and age-matched non-diabetes-prone male $\mathrm{BB}$ rats were obtained from the Department of Pathology, University of Massachusetts, Worchester, MA (courtesy of Dr. A.A. Like) and maintained in individual air-filtered metabolic cages with ad libitum access to water and rat chow (Wayne Lab. Blox F-6, Wayne Laboratory Animal Diets, Wayne Feed Div., Winnipeg, MB, Canada). Body weight, urine volume, glucosuria and ketonuria (Test Tape, Eli Lilly Canada Inc., Toronto, Ont., Canada) were monitored daily, and blood glucose was measured in tail-vein blood samples by Ames Eyetone (Miles Laboratory, Ltd., Rexdale, Ont., Canada) every week, as previously described in detail $[18,22]$.

\section{Diabetic animals (DI and DII)}

One group of five diabetic BB rats was treated with small daily doses of protamine zink insulin (PZI) (0.5-3.0 U/day) from onset of diabetes at 3 months of age to 9 months of age (DI). They were maintained hyperglycemic at blood glucose levels greater than $17 \mathrm{mmol} / 1$. A second group of four diabetic BB rats was maintained at hyperglycemic levels greater than $17 \mathrm{mmol} / \mathrm{l}$ from onset of diabetes at 3 months of age to 9 months of age without ever having received exogenous insulin supplementation (DII). 
Hypoglycemic animals ( $H I$ and HII)

In eight non-diabetic BB rats, age 8.5 months, $h y$ poglycemia was induced by four daily injections of PZI (0.5-4.0 U/day) in order to achieve and maintain blood glucose levels at less than $3.0 \mathrm{mmol} / \mathrm{l}$ for 6 days. Four animals were killed after 6 days of excessive insulin treatment (HI), and four animals were left untreated for an additional 7 days before sacrifice (HII).

\section{Controls (C)}

A group of seven non-diabetic age- and sexmatched BB rats was used as non-diabetic controls (C) and killed at 9 months of age.

\section{Electrophysiological studies}

The day before sacrifice, animals were lightly anesthetized with ethyl ether (Fisher Scientific Co. Fair Lawn, NJ). Motor nerve conduction velocity (MNCV) was determined non-invasively in the sciatic-posterior tibial nerves in a temperature-controlled environment as previously described in detail [28]. The left sciatic-tibial conducting system was stimulated proximally at the sciatic notch and distally at the ankle via bipolar electrodes using supramaximal stimuli $(8 \mathrm{~V})$ from a Tektronix TM 501 stimulator (Tektronix Inc., Beaverton, OR). Evoked muscle potentials were collected from the first interosseous space of the hind paw by a unipolar platinum recording electrode and displayed on a Tektronix 511 storage oscilloscope. MNCV was calculated by subtracting the distal from the proximal latency measured in ms from stimulus artifact to take-off of the evoked muscle potential. The difference was divided into the distance between the stimulating electrodes measured in $\mathrm{mm}$. yielding a value for nerve conduction velocity in $\mathrm{m} / \mathrm{s}$.

\section{Tissue collection}

Animals were anesthetized with sodium phenobarbital $(50 \mathrm{mg} / \mathrm{kg}$ body weight; i.p.) and killed by whole body perfusion with a $0.05 \mathrm{M}$ cacodylatebuffered ( $\mathrm{pH}$ 7.4) $2.5 \%$ glutaraldehyde fixative, which for hyperglycemic animals was adjusted to an osmolality of $500 \mathrm{mosmol}$ with sucrose to achieve serum iso-osmolality. The right sural and tibial nerves, the right spinal ganglion of L5 as well as the L5 segment of the spinal cord were dissected and immersed in the same fixative for $3-4 \mathrm{~h}$ at $4^{\circ} \mathrm{C}$. The specimens were post-fixed in cacodylate-buffered $1 \%$ osmium tetroxide ( $\mathrm{pH} 7.4$ ) for $2 \mathrm{~h}$ at $4^{\circ} \mathrm{C}$, and dehydrated through an ascending series of ethanol. The proximal 3-4 mm of the sural and tibial nerves were used for teased fiber preparations in Epon [16]. The remaining sural and tibial nerves as well as spinal cord segments were embedded in Epon. Semithin sections were used for light microscopic examination and ultra-thin sections were stained with aqueous uranyl acetate and lead citrate for electron microscopic examination.

\section{Quantitative morphometry}

Myelinated fiber size, distribution, density and occupancy in sural and tibial nerves. Semi-thin $(0.5 \mu \mathrm{m})$ toluidine-blue stained transverse sections of the entire unifascicular mainly sensory sural and mixed sensory-motor tibial nerve were photographed, and prints with a magnification of 1000 times were used to calculate the area of each myelinated fiber with the aid of a 9874 A digitizer interfaced with a $9825 \mathrm{~A}$ desk computer and plotter (Hewlett-Packard Co., Cupertino, CA). Composite histograms were compiled for each animal group, in which each fiber size frequency is expressed as a percentage of total fibers, as previously described in detail [16]. The fascicular area of each nerve was digitized from photographic prints with a total magnification of 250 times. Myelinated fiber density per unit area and myelinated fiber occupancy (percent of the fascicular area occupied by myelinated fibers) were calculated as previously described [16].

Axon-myelin ratio. Electron microscopic prints with a total magnification of 20,790 times were used to calculate the ratio between the axonal area $\left(\mu \mathrm{m}^{2}\right)$ and the corresponding myelin sheath thickness expressed by the number of myelin lamellae [16]. A mean of $44.3 \pm 2.7$ systematic randomly chosen fibers from each nerve were examined. 
Density of anterior horn cells and dorsal root ganglion cells. The number of $\alpha$ motoneurons of the anterolateral anterior horn and of dorsal root ganglion cells of the L5 segment was calculated from photographic prints at a total magnification of 500 times obtained from semi-thin $(0.5 \mu \mathrm{m})$ toluidineblue stained sections. From each tissue block four sections were examined $30 \mu \mathrm{m}$ apart. Neurons were counted and the areas of neuropil occupied by motoncurons and ganglion cells were digitized yielding nerve cell densities $\left(n / \mathrm{mm}^{2}\right)$. A split cell error correction factor of 0.542 was used for both $x$ motoneurons and dorsal root ganglion cells [29].

Teased fiher analysis of sural and tibial nerves. The spectrum of abnormal myelinated fibers was assessed by analysis of teased fibers. A mean of $63 \pm$ 5 randomly teased single fibers from each nerve was examined light microscopically at a magnification of 480 times. Each fiber was assigned to one of eight categories based on characteristic structural features according to a modification [9] of the technique described by Dyck et al. [8]: (A) normal fibers; (B) paranodal swelling defined as a paranodal diameter $>150 \%$ of the internodal diameter; (C) paranodal demyelination: (D) excessive myelin wrinkling; (E) intercalated (remyelinated) nodes; (F) Wallerian degeneration: $(G)$ segmental demyelination; $(\mathrm{H})$ regencrated and/or remyelinated fibers. The frequencies of abnormalities were expressed as a percentage of fibers examined.

\section{Statistical analysis}

The results are presented as mean \pm SEM. and significance of difference was calculated using ANO$V A$ followed by modified $t$-test. Linear regression analysis was performed by the method of least squares. The comparison of myelinated fiber size distributions was performed using chi-square distribution. and the individual size frequencies were compared using Student's $t$-test.

\section{Results}

\section{Clinical observation}

Prediabetic rats $(n=9)$ developed diabetes at $94 \pm$ 8 days of age and were persistently hyperglycemic for $182 \pm 9$ days. At time of sacrifice diabetic rats receiving small maintenance doses of insulin (DI) and those receiving no exogenous insulin (DII) showed similar degrees of hyperglycemia (Table 1). Diabetic rats (DI and DII) demonstrated a significant $(P<0.001)$ reduction in body weight gain as well as a $26 \%$ slowing of MNCV (Table 1). Hypoglycemic animals were never rendered comatose and after 1 week of excessive insulin treatment showed blood glucose levels of approximately half the normal control value (Table 1). One group killed immediately after 6 days of excessive insulin treatment (HI) showed no significant body weight loss, whereas animals maintained for an additional week (HII) demonstrated an $18 \%(P<0.05)$ weight loss (Table 1). MNCV in hypoglycemic animals was $19 \%$ slower than in age-matched controls (Table 1). Hyperglycemic BB rats exhibited no gross neurological deficits, whereas rats in whom hypoglycemia was induced revealed after 3-4 days of insulin injection weakness of the extremities, particularly pronounced in the hind legs. This weakness disappeared 4-5 days after insulin injections were discontinued in the HII group, except for one animal who showed persistent weakness.

\section{Quantitative morphology in sural nerve}

Hypoglycemic animals $(H I$ and $H I I)$. Insulin-induced hypoglycemia resulted in significant shifts in sural nerve fiber caliber spectra toward smaller fibers as compared with non-diabetic controls $(P<$ $0.001)$ due to a decrease in the frequencies of large myelinated fibers (Fig. 1a). The loss of large myelinated fiber sizes in hypoglycemic rats was also reflected in a significant $(P<0.0001)$ reduction in 
TABLE I

CLINICAL DATA AT TIME OF SACRIFICE

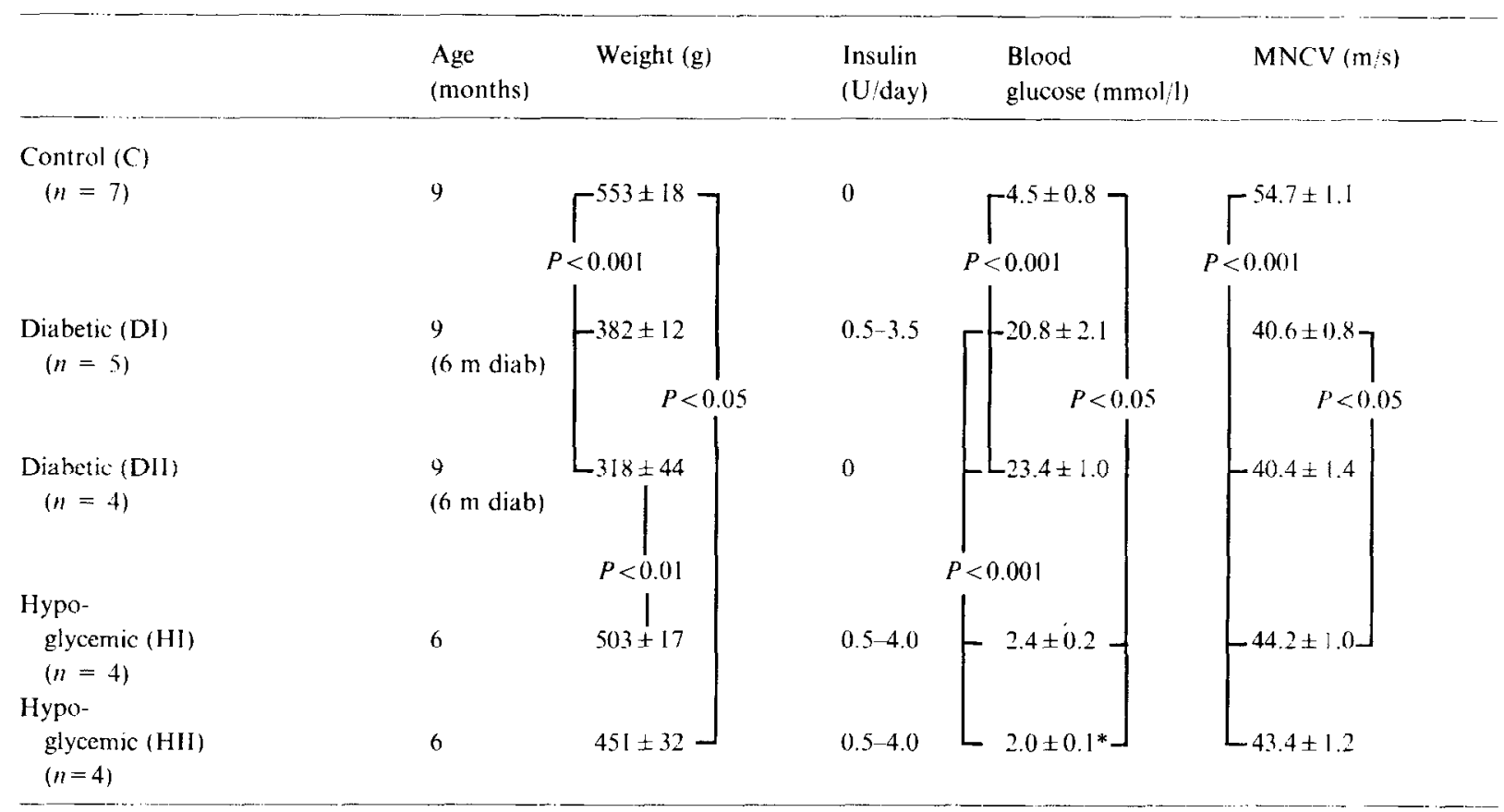

Comparisons of body weight, daily insulin dose, blood glucose levels and motor nerve conduction velocities in hyperglycemic animals with (DI) and without (DII) insulin supplementation and hypoglycemic animals immediately after 6 days of insulin-induced hypoglycemia $(\mathrm{HI})$ and 7 days following 6 days of insulin-induced hypoglycemia (HII). The values (mean \pm SEM) are compared with those obtained from non-diabetes-prone euglycemic control rats.

* Blood glucose values reflect those at termination of insulin treatment.

mean myelinated fiber size (Table 2). Myelinated fiber density was moderately $(P<0.02)$ increased in acutely hypoglycemic rats (HI) while fiber occupancy was unchanged when compared with nondiabetic controls (Table 2 ), probably reflecting a significant $(P<0.001)$ increase in regenerating sural nerve fibers (see column $\mathrm{H}$. Table 3 and below). Hypoglycemic animals who were allowed to survive for an additional week (HII) showed a similar reduction in mean fiber size (Table 2), whereas fiber density was normalized and fiber occupancy was decreased to $61 \%$ of normal (Table 2), in keeping with loss of large myelinated fibers and the addition of small regenerating fibers. The axon-myelin ratios (regression coefficients b in Fig. 2a) were significantly decreascd in both hypoglyccmic groups $(P<$ 0.001 ) (HI and HII in Fig. 2a) compared with nondiabetic control rats ( $\mathrm{C}$ in Fig. 2a), suggesting that axonal atrophy may, in addition to loss of large myelinated fibers, have accounted for the decrease in myelinated fiber size in hypoglycemic rats.

Hyperglycemic animals (DI and DII). Similar to hypoglycemic animals diabetic rats showed highly significant shifts $(P<0.001)$ of myelinated fiber caliber spectra toward smaller fiber sizes (Fig. 1b). These shifts in caliber size distribution were due to a simultaneous decrease in the frequencies of large myelinated fibers and an increase in the frequencies of small myelinated fibers (Fig. 1b). The fiber size distribution in diabetic rats maintained on small doses of insulin (DI) was not markedly different from that in diabetic rats maintained on no insulin (Fig. 1c). Mean myelinated fiber size was significantly reduced $(P<0.0001)$ in both diabetic groups (Table 2). Myelinated fiber densities were increased 
with approximately $15 \%$ in both groups, whereas fiber occupancies showed no significant change ( $T a-$ ble 2), in keeping with shrinkage of the endoneurial space and a substantial atrophy of myelinated fibers as previously reported [16]. Axon-myelin ratios in both diabetic groups revealed similar and significant decreases $(P<0.001)$ (DI and DII in Fig. 2a) compared with non-diabetic control rats ( $\mathrm{C}$ in Fig. 2a), suggesting that axonal atrophy may account for myelinated fiber atrophy. Axon-myelin ratios in

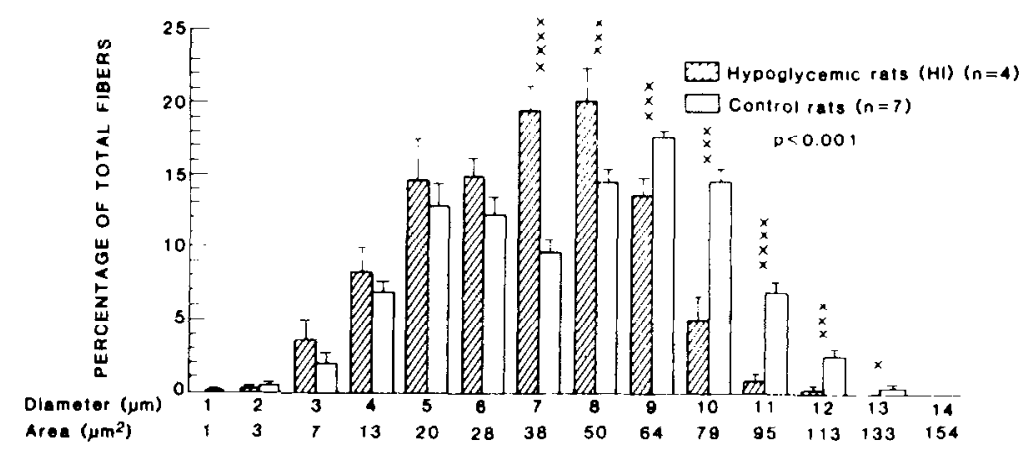

$1 a$

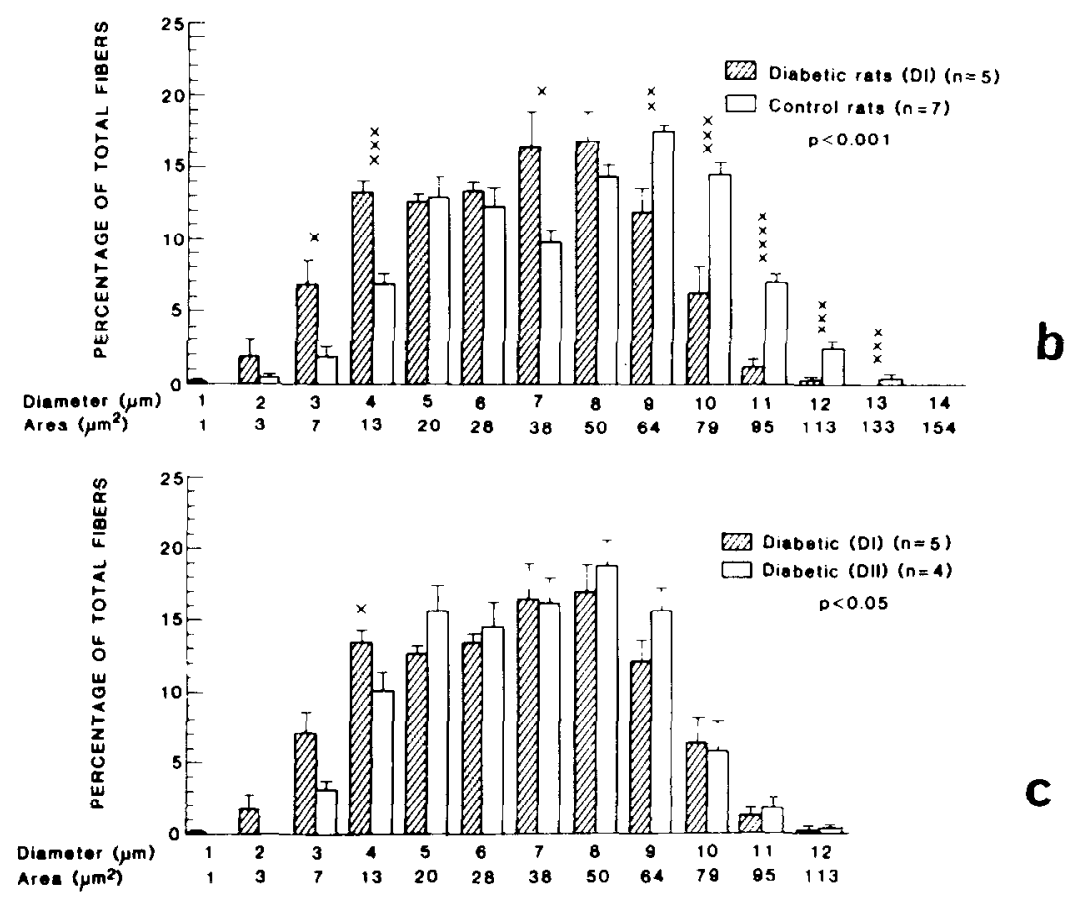

Fig. I. Myelinated fiber areas were measured from photographic prints, taken from toluidine blue cross-sections of the unifascicular sural nerve and magnified 1000 times. Histograms were constructed, in which each fiber size frequency is expressed as a percentage of total fibers. The fiber size distributions are compared using chi-square distribution and significance of difference is indicated in a. b and c. (a) Hypoglycemic rats killed immediately following a 6-day period of excessive insulin injections (HI) are compard with age- and sexmatched control rats $(C)$. The frequencies of large myelinated fibers are markedly decreased, indicating loss of large myelinated fibers. (b) Myelinated fiber caliber spectra of diabetic rats treated with small maintenance doses of insulin (DI) and control rats (C) are compared. In diabetic rats the frequencies of large fibers are decreased, while those of small fibers are increased, suggesting a generalized atrophy of fibers. (c) Myelinated fiber size frequencies of diabetic rats with insulin supplementation (DI) are compared with those of diabetic rats who never received exogenous insulin (DII). No major differences are demonstrated in myelinated fiber size distribution between the two diabetic groups $\times, P<0.05: \times \times, P<0.02: \times \times \times, P<0.01: \times \times \times \times, P<0.001$. 
TABLE 2

NUMERICAL MORPHOMETRIC DATA OF SURAL NERVES

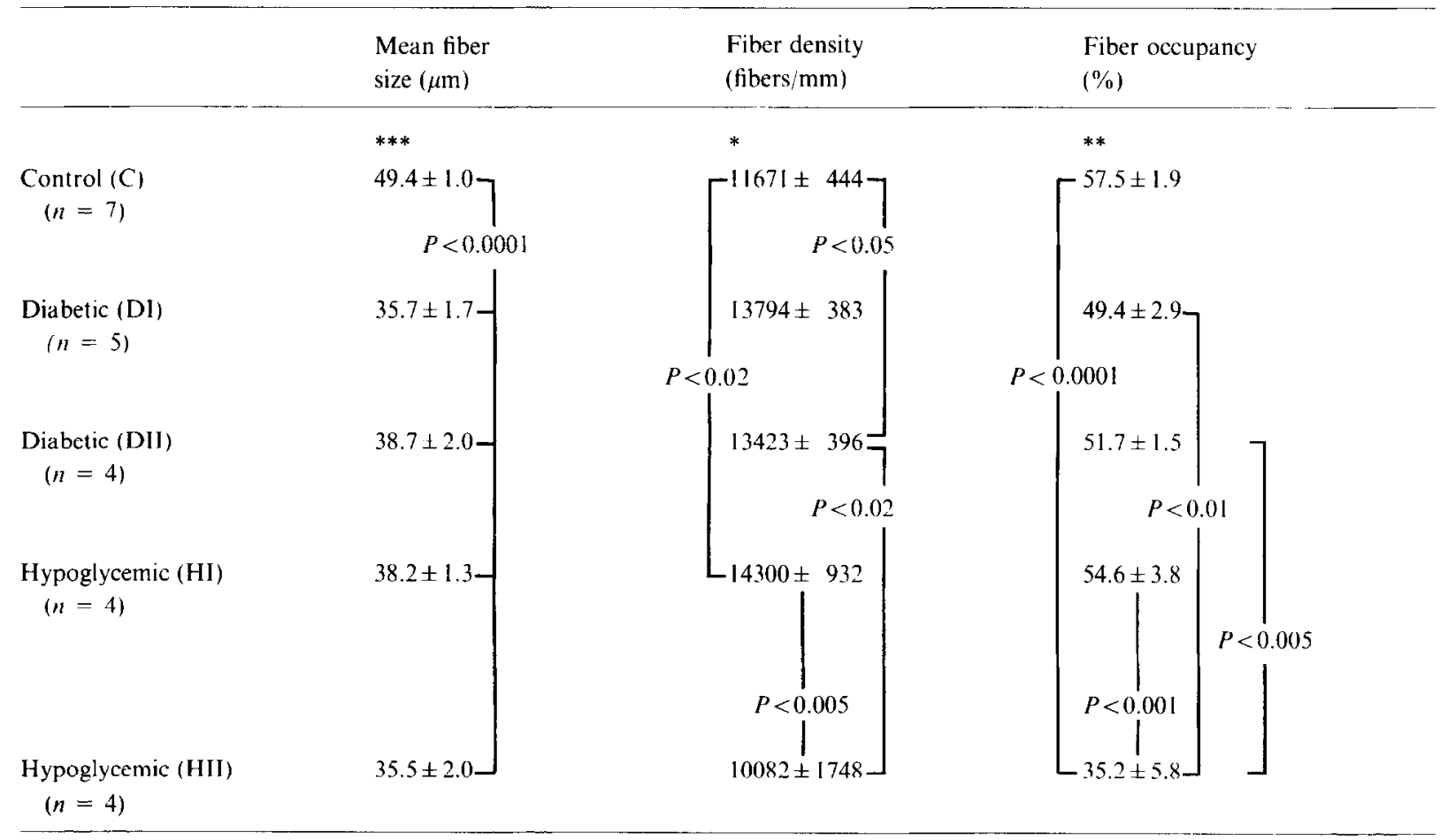

Comparison of mean myelinated fiber size, myelinated fiber density and occupancy (endoneurial area occupied by myelinated fibers) between the various experimental groups. Values are expressed as mean $\pm \mathrm{SEM}$.

*** ANOVA $P<0.0001$.

** ANOVA $P<0.001$.

* ANOVA $P<0.02$.

diabetic rats were not different from those calculated from sural nerves of hypoglycemic animals (Fig. 2a).

\section{Teased fiber analysis of sural nerve}

Hypoglycemic animals (HI and HII). Excessive insulin treatment resulted in a marked decrease in the frequencies of normal fibers in the HI group to $48 \%$ of total fibers and an additional significant ( $P$ $<0.0001$ ) decrease to $30 \%$ in rats allowed to survive the hypoglycemic 6-day period for another 7 days (Table 3). This decrease was to a large extent accounted for by significant increases in the frequencies of fibers exhibiting Wallerian degeneration, which increased from $13 \%$ in the HI group to
$38 \%$ in the HII group (Table 3 ), as well as marked $(P<0.005)$ increases in the frequencies of fibers exhibiting excessive myelin wrinkling (approximately $15 \%$ in both groups). Other abnormalities which were demonstrated in single teased fibers included paranodal swelling, paranodal demyelination, intercalated nodes, and segmental demyelination which were all increased compared with nondiabetic control rats (Table 3).

Hyperglycemic animals $(D I$ and $D I I)$. The frequencies of normal fibers were reduced in both hyperglycemic groups $(P<0.0002)$ compared to nondiabetic control rats with no intergroup difference (Table 3). Nevertheless, normal fibers were still demonstrated approximately twice as frequently in 


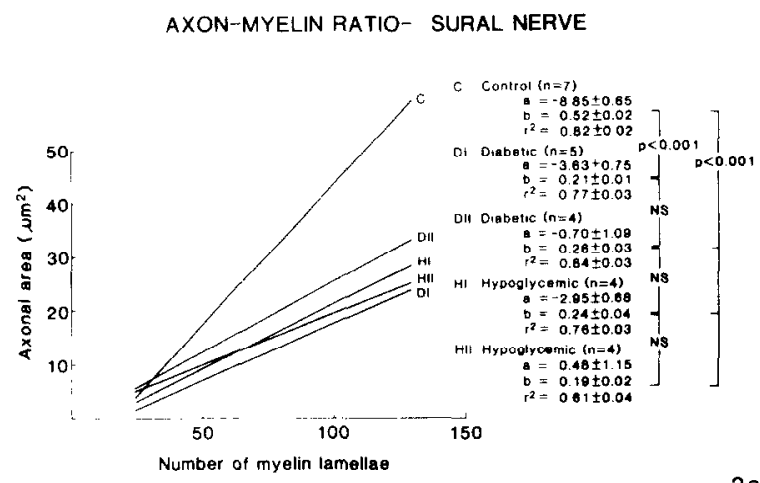

AXON-MYELIN RATIO- TIBIAL NERVE

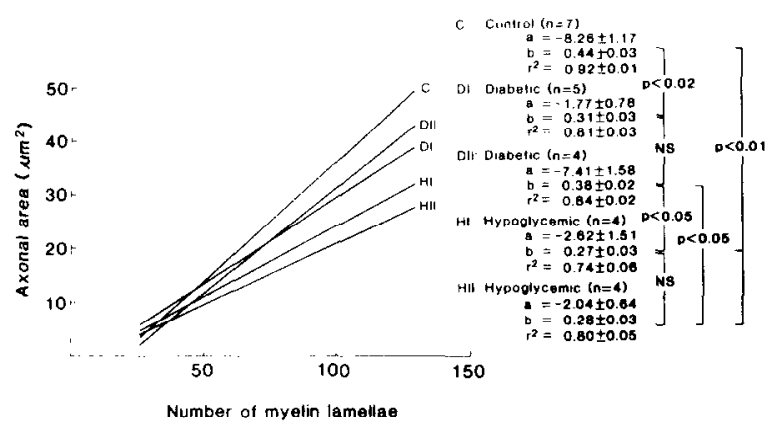

$2 b$

Fig. 2. Axon-myelin ratio was calculated from measurements of axonal area and the thickness of the corresponding myelin sheath, expressed as the number of myclin lamellae. The slopes of the linear regressions ( $b$ in the equation $y=a+b x$ ) obtained from each nerve were compared between groups. (a) Intergroup comparisons of the sural nerve axon myelin ratios. Both diabetic groups (DI and DII) as well as both hypoglycemic groups (HI and HII) are significantly decreased compared with age- and sexmatched control rats $(C)$. The decrease in axon-myelin ratio, indicating axonal atrophy. was similar in diabetic and hypoglycemic rats and did not differ between the two diabetic (DI and DII) or the two hypoglycemic groups (HI and HII). (b) The same comparisons are made between axon-myelin ratios in the tibial nerve. The axon-myelin ratio was only marginally decreased in diabetic rats, reaching significance in diabetic rats treated continuously with insulin (DI), when compared with control rats (C). Hypoglycemic rats ( $\mathrm{HI}$ and $\mathbf{H I I}$ ) showed a slighlly nore severe decrease in their axon-myelin ratios compared with control rats (C), and they were significantly $(P<0.05)$ lower when compared with non-insulin-treated diabetic rats (DII).

hyperglycemic rats as in hypoglycemic animals (Table 3 ). The most commonly encountered abnormality in diabetic nerves was excessive myelin wrinkling (Table 3) which reflects axonal atrophy [9]. Myelin wrinkling was slightly more common in non-insulin-treated diabetic rats (Table 3), while still approximately half as frequent as in rats with induced hypoglycemia. Other previously described abnormalities in teased myelinated fibers of the diabetic BB rat included paranodal swelling and demyelination, intercalated nodes, segmental demyelination, as well as regenerating fibers (Table 3). Paranodal swelling was significantly $(P<0.002)$ more frequent in diabetic rats compared with hypoglycemic animals (HII), whereas paranodal demyelination occurred with similar frequencies in diabetic and hypoglycemic rats. In contrast, intercalated nodes, segmental demyelination and regenerating fibers tended to be more frequent in hypoglycemic rats (Table 3).

\section{Quantitative morphology in tibial nerve}

Hypoglycemic animals (HI and HII). Also in the tibial nerve the caliber spectra of myelinated fibers were shifted toward smaller fiber sizes $(P<0.001)$ (Fig. 3a) which was associated with a $20 \%$ reduction in mean fiber size $(P<0.0001)$ (Table 4$)$. These changes probably reflect Wallerian degeneration and loss of predominantly large myelinated fibers, whereas myelinated fibers of lesser size appeared to be relatively spared (Fig. 4). No changes were demonstrated in fiber densities, whereas fiber occupancies were significantly reduced when compared with age-matched control rats $(P<0.02$ and $P<0.001$ in HI and HII respectively compared to $C$ in Table 4). This discordance in fiber density and occupancy probably reflects loss of large myclinated fibers which are partly replaced by small regenerating fibers (see column $\mathrm{H}$ in Table 5), and a noticeable endoneurial edema in hypoglycemic tibial nerves. further decreasing the already diminished occupancy by small regenerating fibers (Fig. 5). The axon-myelin ratios of tibial nerve fibers in hypoglycemic animals were markedly reduced compared with non-diabetic control animals $(P<0.01)$ (compare $\mathrm{HI}$ and HII with $\mathrm{C}$ in Fig. 2b) and were also reduced $(P<0.05)$ compared with hyperglycemic animals receiving no continuous insulin supplementation (DII in Fig. 2b). Thus the greater decrease in 

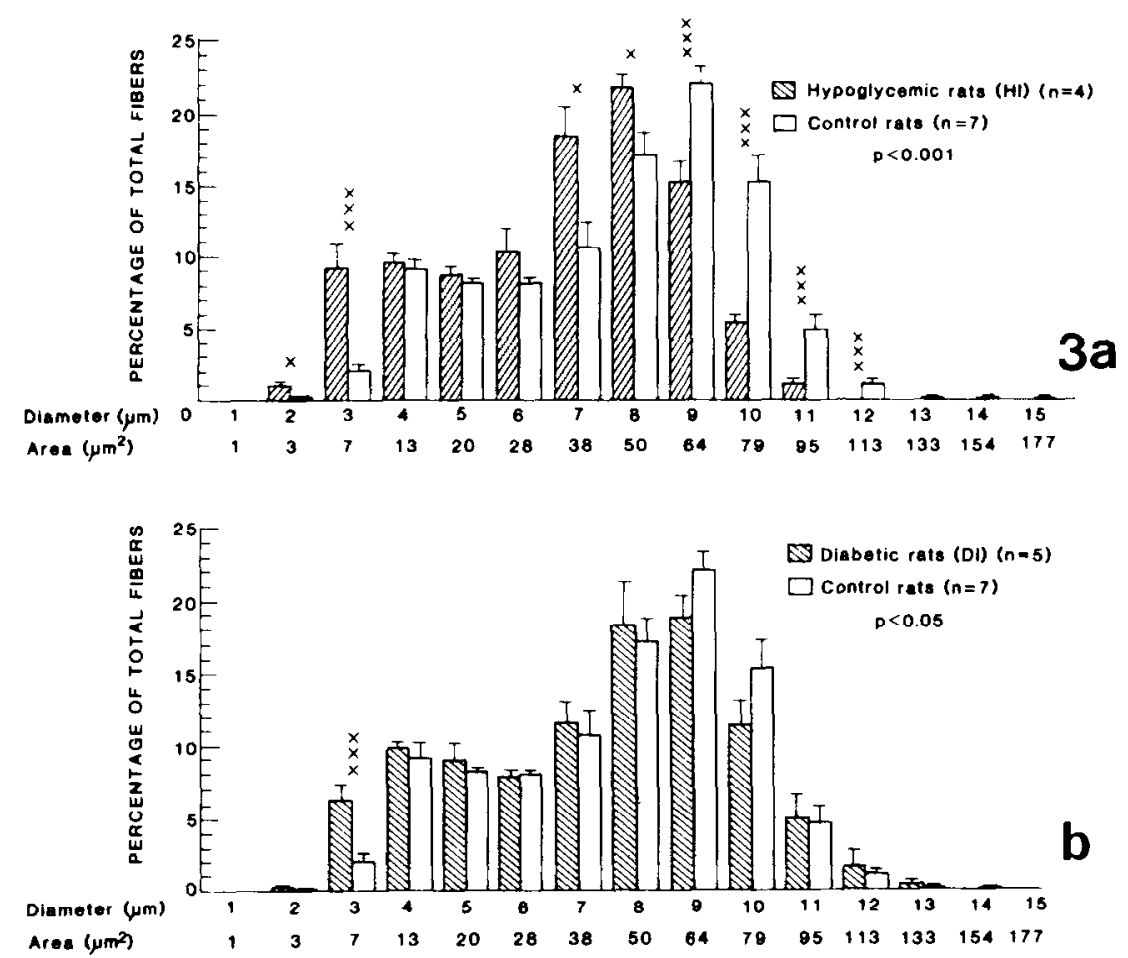

Fig. 3. Myelinated fiber size distributions in tibial nerves were calculated and constructed in the same way as for sural nerves. (a) Acutely hypoglycemic rats $(\mathrm{HI})$ are compared with age- and sex-matched controls (C). Similar to the changes seen in the sural nerve, hypoglycemic rats exhibited marked decreases in the frequencies of large myelinated fibers, most likely representing loss of this fiber category. In addition. hypoglycemic rats showed a small increase in the smallest fibers, probably representing the addition of small newly regenerated myelinated fibers. (b) Myelinated fiber size distributions in insulin-treated diabetic rats (DI) and control rats (C) are compared. No significant differences are demonstrated, except for $3 \mu \mathrm{m}$ fibers which are increased in diabetics, probably reflecting the significant increase in regenerating fibers (compare column $\mathrm{H}$ in Table 5 ).

myelinated fiber size in hypoglycemic rats compared with hyperglycemic animals (Table 4) may in part reflect a more severe axonal atrophy in the former groups.

Hyperglycemic animals (DI and DII). Only minimal shifts toward smaller fiber sizes were demonstrated in myelinated fiber caliber spectra of the tibial nerve (Fig. 3b). Mean myelinated fiber size was only moderately $(P<0.02)$ reduced in diabetic animals receiving insulin compared with age-matched control rats (compare DI with $C$ in Table 4). However, the mean myelinated fiber size in hyperglycemic animals was greater than in both hypoglycemic groups (compare DI and DII with HI and HII in Table 4). No differences were demonstrated in fiber densities when compared with non-diabetic control rats or hypoglycemic rats (Table 4). Myelinated fiber occupancy was not reduced in diabetic rats receiving small maintenance doses of insulin, whereas those receiving no insulin showed a $20 \%$ reduction in fiber occupancy $(P<0.02)$ (Table 4$)$. The moderate change in mean myelinated fiber size in the tibial nerve in hyperglycemic animals receiving insulin supplementation (Table 4 ) corresponded to a moderate decrease $(P<0.02)$ in the axon-myelin ratio (Fig. 2b), whereas diabetic animals receiving no insulin exhibited no significant change in the axon-myelin ratio (Fig. 2b).

\section{Teased fiber analysis of tibial nerve}

Hypoglycemic animals ( $H I$ and $H I I)$. The pattern of single teased fiber abnormalities in the tibial 

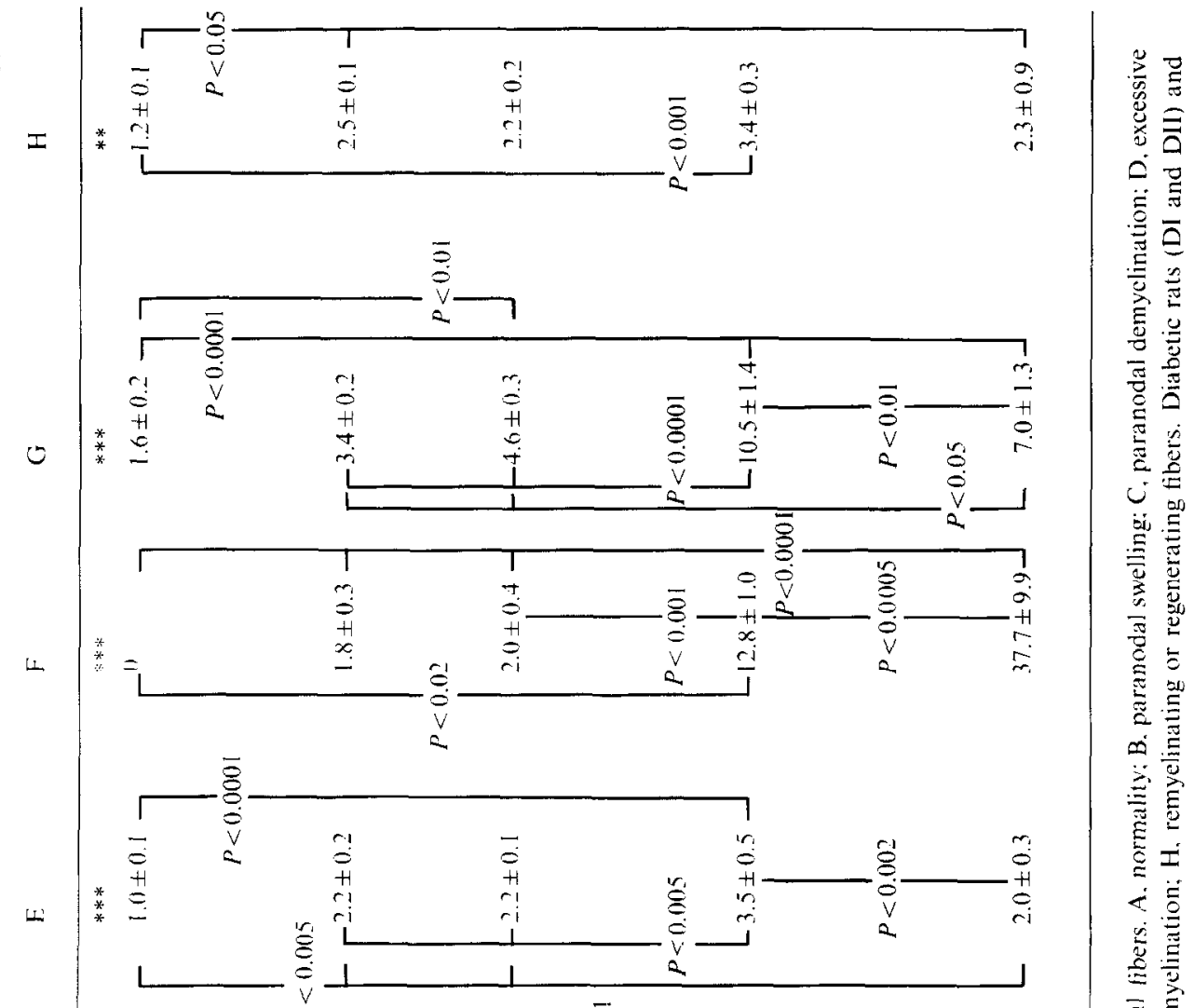

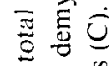

志节

跒

浣

运

吃产

正焉

콩

合

03

比要

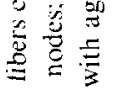

氜总总

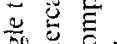

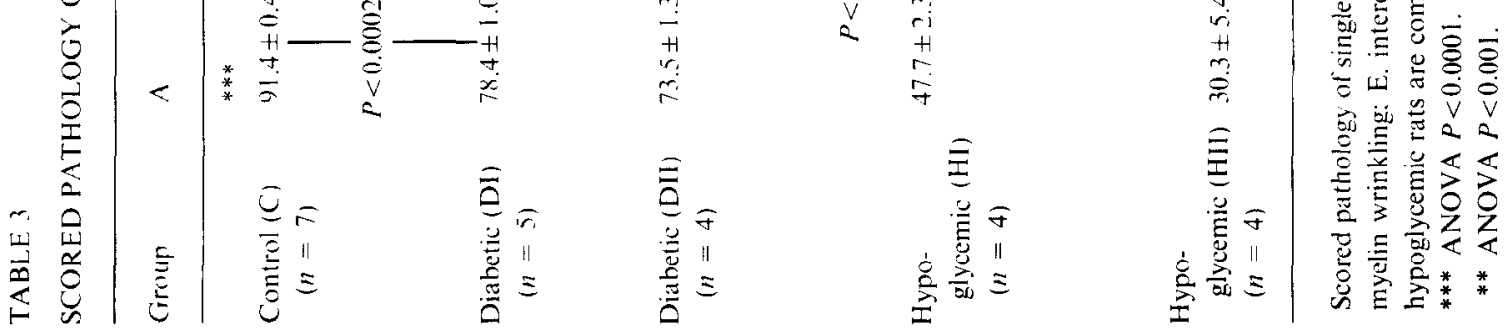

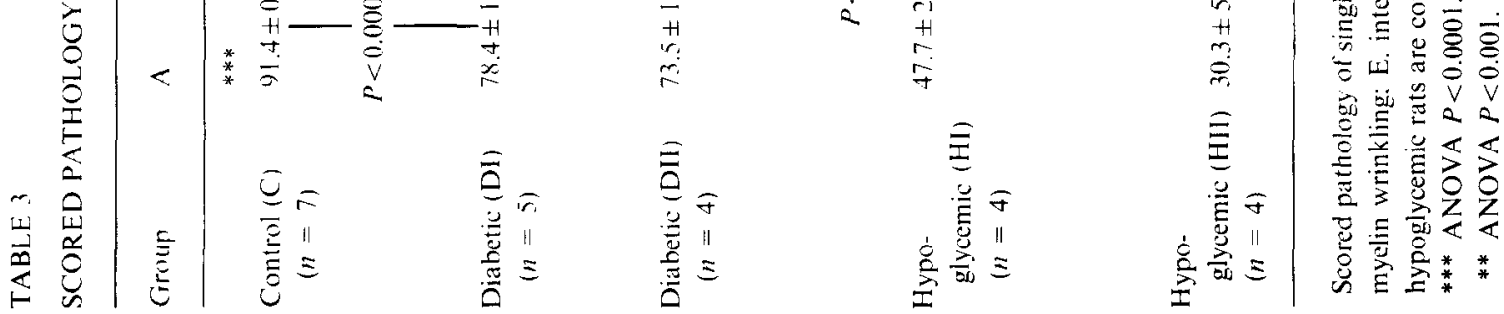


TABLE 4

NUMERICAL MORPHOMETRIC DATA ON TIBIAL NERVES

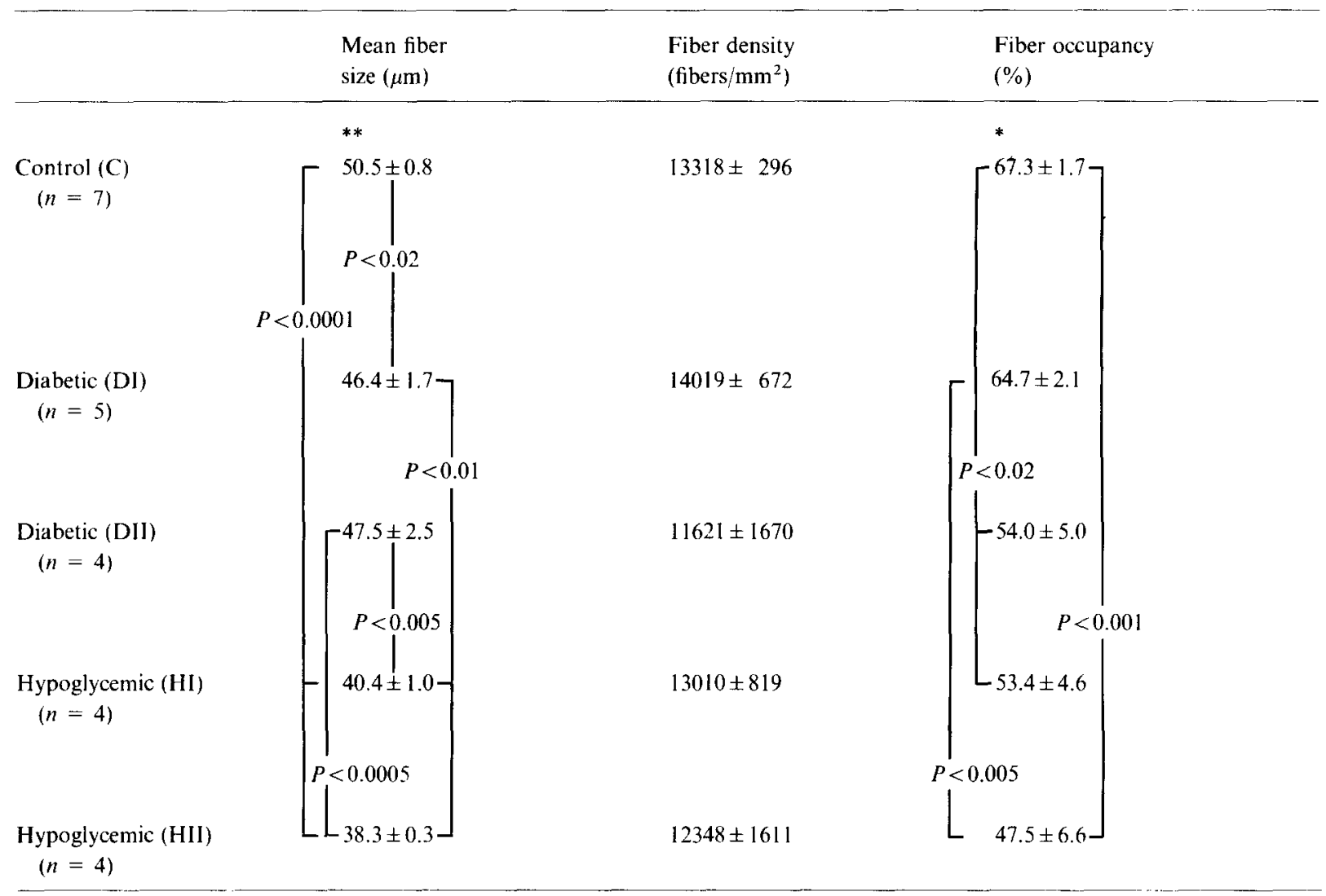

Mean myelinated fiber size, fiber density and fiber occupancy of tibial nerves are compared in diabetic, hypoglycemic and non-diabetesprone control rats.

** ANOVA $P<0.0001$.

* ANOVA $P<0.005$

nerve was similar to that in the sural nerve (Table 5). Excessive myelin wrinkling, characterizing axonal atrophy and Wallerian degeneration, was more frequent in tibial nerves from hypoglycemic animals killed 1 week after excessive insulin treatment (HII) (Fig. 4) than in those killed immediately following insulin treatment $(\mathrm{HI})$ (Table 5).

Hyperglycemic animals (DI and DII). The frequency of single teased myelinated fiber abnormalities in tibial nerves of diabetic rats showed a similar distribution to that exhibited by sural nerves. The frequencies of fibers showing excessive myelin wrin- kling and regenerating fibers appeared to be somewhat greater in the tibial nerve compared with the sural nerve (compare columns $\mathrm{D}$ and $\mathrm{H}$ in Table 5 with those in Table 3). Paranodal swelling was significantly $(P<0.001)$ more frequent in diabetic rats receiving no insulin supplementation than in hypoglycemic rats (Table 5).

Density of $\alpha$ motoneurons and dorsal root ganglion cells

Hypoglycemic animals ( $H I$ and $H I I)$. The density of $\alpha$ motoneurons of the L5 segment of the spinal 


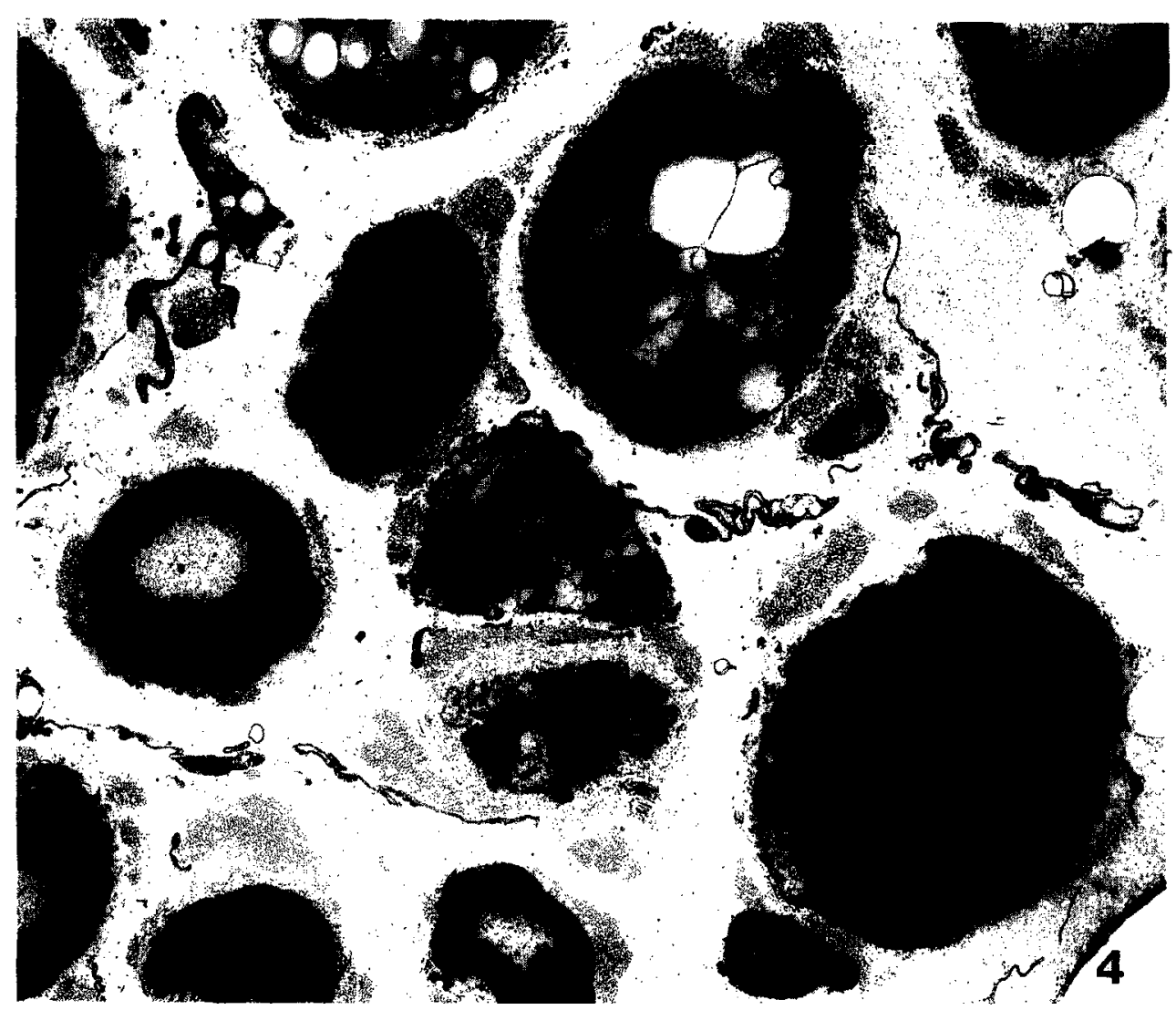

Fig. 4. Electron micrograph of the tibial nerve in an acutely hypoglycemic rat (HI). There are several large myelinated fibers showing various stages of Wallerian degeneration as well as smaller sized myelinated fibers showing axonal atrophy with wrinkling of the myelin sheaths. $4400 \times$.

cord was reduced to approximately $60 \%$ of normal in both hypoglycemic groups $(P<0.001$ and $P<$ 0.002 for $\mathrm{HI}$ and $\mathrm{HII}$ respectively; Table 6$)$. The loss of dorsal root ganglion cells, as reflected by their density, was less severe but increased following the discontinuation of excessive insulin treatment. In acutely hypoglycemic rats $(\mathrm{HI})$ the density was reduced to $80 \%(P<0.05)$ with a further reduction to $65 \%$ ( $P<0.001)$ of normal I week following the period of hypoglycemia (HII) (Table 6).

Hyperglycemic animals (DI and DII). No significant loss of $\alpha$ motoncurons or dorsal root ganglion cells could be demonstrated in either diabetic group (DI and DII in Table 6).

\section{Discussion}

The diabetic neuropathy occurring in the spontaneously diabetic BB rat has previously been characterized as a mainly sensory distal axonopathy $[16,17,20]$. The present findings tend to confirm this, since myelinated fiber atrophy was more pronounced in the mainly sensory sural nerve than in the mixed sensory-motor tibial nerve. Diabetic animals failed in the present study to show any loss of sensory ganglion cells in the dorsal root ganglia or loss of $\alpha$ motoneurons in the anterior horn, suggesting that the axonopathy is not the consequence of an underlying neuronopathy.

Myelinated fiber atrophy occurring in diabetic 


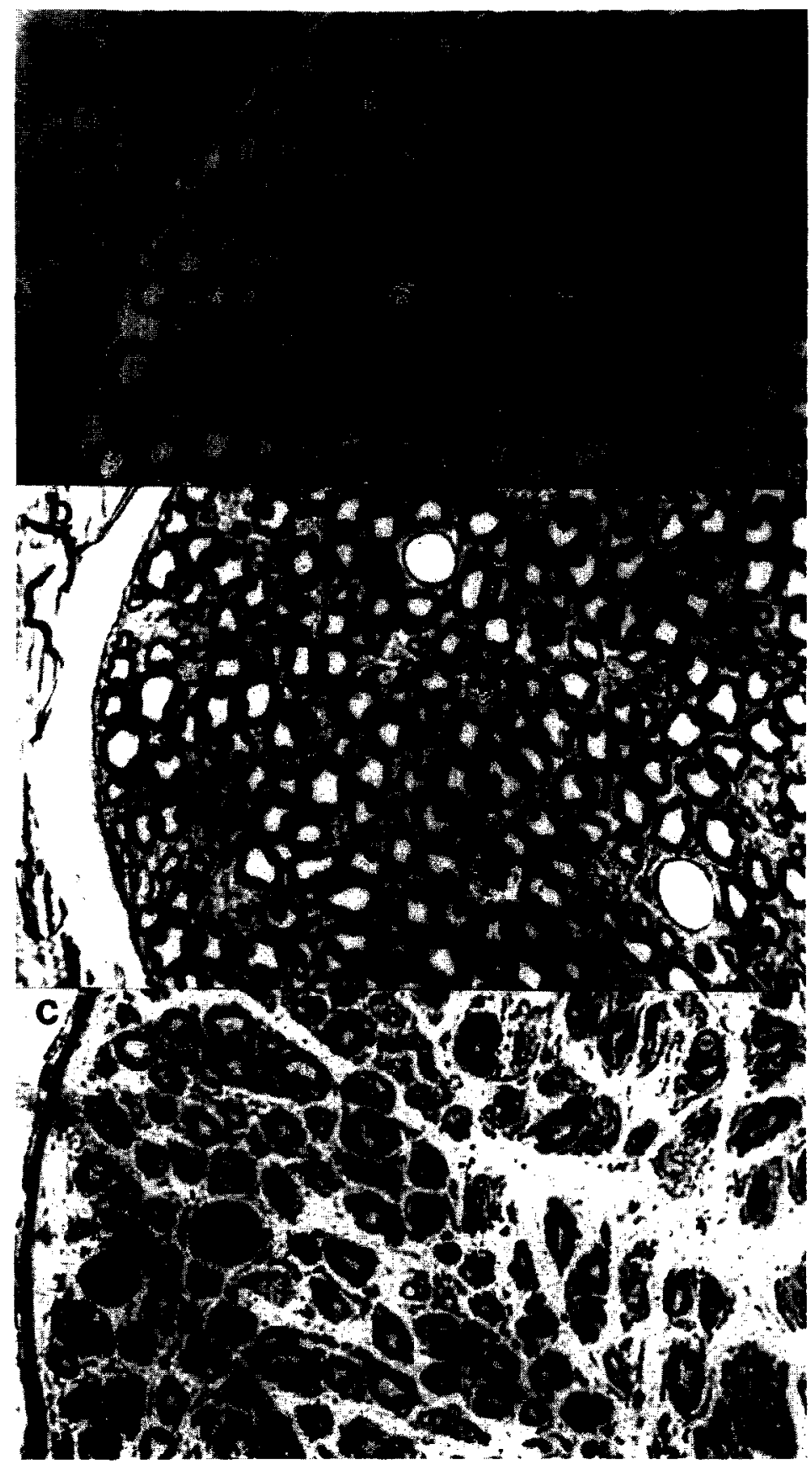

Fig. 5. Micrographs of tibial nerves in (a) a control rat; (b) non-insulin-treated diabetic rat (DII); and (c) hypoglycemic rat killed 1 week following hypoglycemia (HII). In b, axonal atrophy is evident by the irregular myelin sheaths. In c, there is marked loss of large myelinated fibers, some of which are still undergoing Wallerian degeneration (left part in c). In addition there is endoneurial edema, which in part may explain the discordance between fiber density and fiber occupancy in this hypoglycemic group (HII) (compare Table 4). 


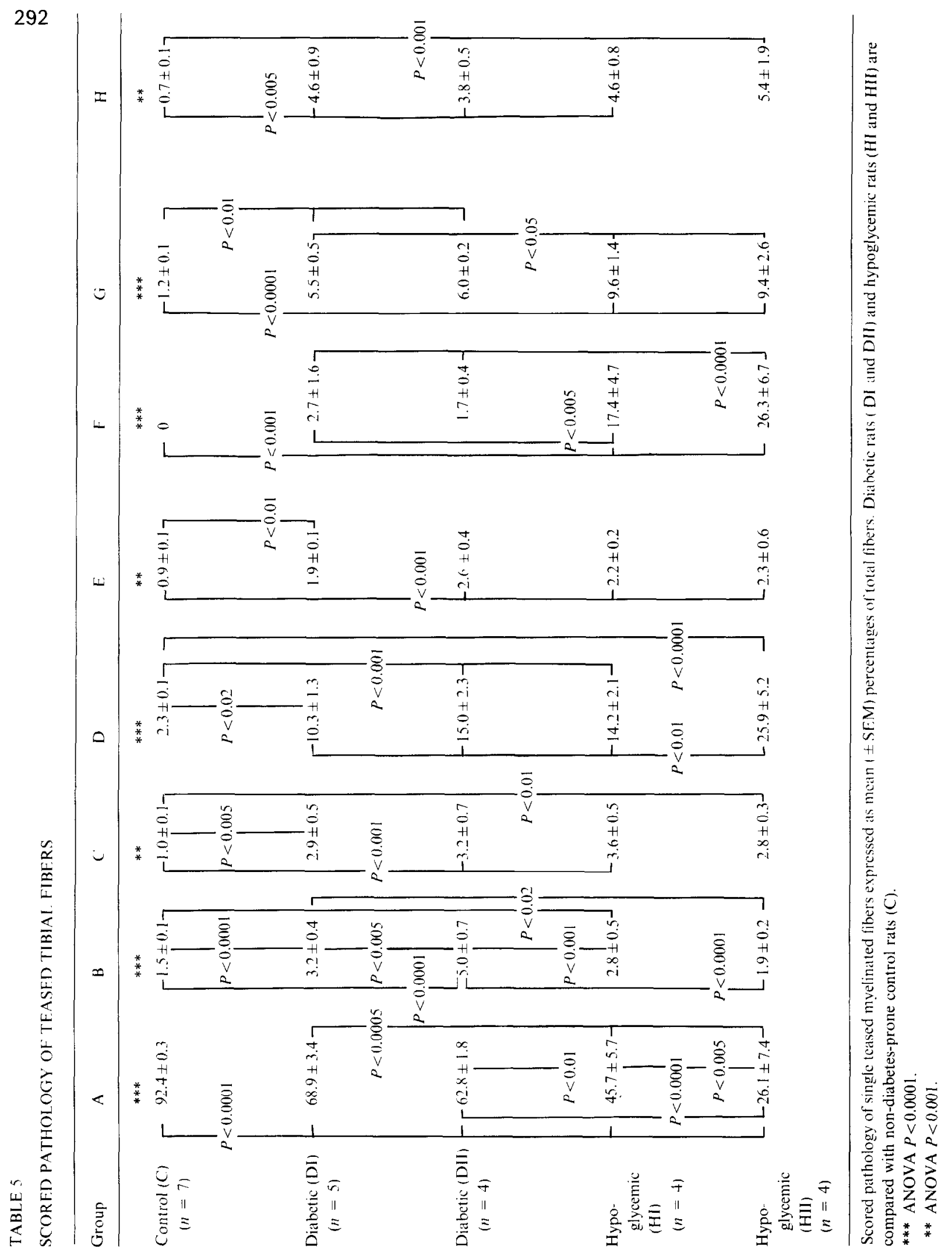


TABLE 6

DENSITY OF ALPHA MOTONEURONS AND DORSAL ROOT GANGLION CELLS

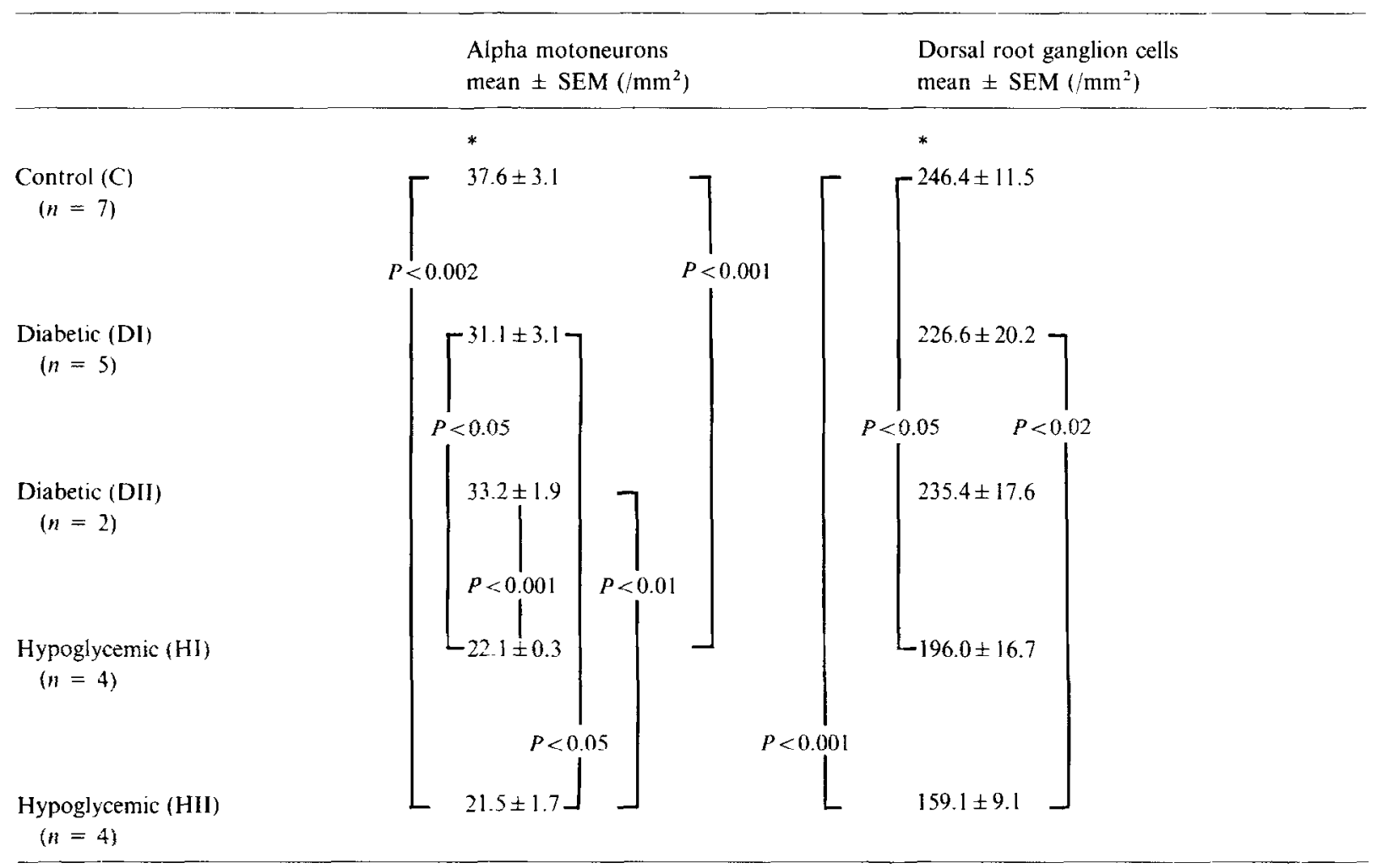

The density of $\alpha$ motor neurons of the L5 segment and dorsal root ganglion cells of L5 expressed as number of cells per mm ${ }^{2}$ is compared in the various experimental groups.

* ANOVA $P<0.01$.

polyneuropathy appears to be primarily due to axonal atrophy as demonstrated by axon-myelin ratios and increased frequencies of fibers exhibiting excessive myelin wrinkling. As illustrated by these morphometric parameters, axonal atrophy appears to affect the mainly sensory sural nerve more severely than the mixed sensory-motor tibial nerve $[16,30]$.

Additional structural abnormalities previously described in peripheral nerve of the diabetic BB rat and human diabetic neuropathy involve the node of Ranvier, such as nodal and/or paranodal axonal swelling, paranodal demyelination, and remyelination $[9,12,13,18]$. These findings were confirmed by the present teased fiber analysis.

Continuous supplementation of small insulin doses to diabetic $\mathrm{BB}$ rats did not have an additional deleterious effect on the severity of the neuropathy, nor did it seem to alter the nature of the neuropathy when compared with diabetic BB rats that did not receive exogenous insulin but were maintained at similar hyperglycemic levels throughout their course of diabetes. On the contrary, non-insulinsupplemented rats tended to develop a more severe expression of the characteristic structural abnormalities of diabetic neuropathy, such as paranodal swelling and excessive myelin wrinkling suggesting a small beneficiary effect of even small continuous insulin injections. These structural abnormalities in diabetic rats were paralleled by a similar decrease in motor nerve conduction velocity in the two diabetic groups.

Thus it is unlikely that the ncuropathy develop- 
ing in the spontaneously diabetic BB rat with exogenous insulin supplementation is a consequence of the usually necessary exogenous insulin treatment and/or its vehicle, as has been previously suggested [24.25].

In order to examine the possibility that previously reported morphological findings in insulin-treated diabetic rats $[24,25]$ may have been misinterpreted and instead represent hypoglycemic peripheral nerve damage arising from even short periods of hypoglycemia $[31,32]$, peripheral nerves were examined from two groups of $\mathrm{BB}$ rats exposed to hypoglycemia. The prevailing structural findings in these animals were Wallerian degeneration. segmental demyelination, and axonal atrophy which are in agreement with those previously reported in both experimental animals $[31,32]$ and in man $[33-$ 35] consequent to hypoglycemia. They are similar to the findings reported in insulin-treated diabetic rats by Mandelbaum and collaborators [24,25] who demonstrated an eightfold increase in the frequency of fibers exhibiting Wallerian degeneration compared with non-insulin-treated diabetic rats.

The high frequencies of myelinated fibers exhibiting Wallerian degeneration in both the sural and tibial nerves corresponded to marked losses of dorsal root ganglion cells and anterior horn $x$ motoneurons, abnormalities which were not demonstrable in diabetic rats. These findings, therefore, confirm that prolonged severe hypoglycemia affects primarily the cell bodies with subsequent Wallerian degeneration $[31.32,35]$.

In contrast to diabetic neuropathy which involves mainly sensory fibers, hypoglycemic neuropathy appears to affect motor fibers more severely as reflected by a larger loss of motoneurons compared to sensory neurons, and by a more severe reduction in mean fiber size in the sensory-motor tibial nerve compared with the mainly sensory sural nerve. The increased vulnerability of motoneurons versus sensory ganglion cells in hypoglycemic BB rats appears to be similar to the situation in man as reflected by clinical findings and electrophysiologic deficits reported in a few patients with hypoglycemia [34,3639]. In addition to the acute effect of glucopenia on motoneurons. a prolonged and progressive adverse effect on nerve morphology was evident following discontinuation of hypoglycemic exposure with an accentuation of Wallerian degeneration and axonal atrophy.

In summary therefore, it is unlikely that continuous small insulin dosing in the spontaneously diabetic $\mathrm{BB}$ rat has any etiological relevance with respect to the development of diabetic neuropathy in this model. In contrast, it may have a marginally beneficiary effect on this complication despite the fact that the rats are maintained at severely hyperglycemic levels. Hypoglycemia in the same model causes an acute and progressive severe neuropathy resulting in neurological deficits and slowing of $\mathrm{MNCV}$. In contrast to diabetic neuropathy, hypoglycemic nerve damage tends to affect motor fibers more than sensory fibers and might be characterized as a neuronopathy rather than an axonopathy.

\section{Acknowledgements}

This study was supported in part by grants from the JDFI, New York, NY, and from the Medical Research Council of Canada (MA-8681 and MA-9351). The authors are indebted to Mrs. Jackie McKane for preparing the manuscript.

\section{References}

1 Behse, F., Buchtal, F. and Carlson, F. (1977) Nerve biopsy and conduction studies in diabetic neuropathy. J. Neurol. Neurosurg. Psychiatry 40, 1072-1082.

2 Hansen, S. and Ballantyne, J.P. (1977) Axonal dysfunction in the ncuropathy of diabetes mellitus: a quantitative electrophysiological study. J. Neurol. Neurosurg. Psychiatry 40. 555-564.

3 Bischoff, A. (1973) Ultrastructural pathology of peripheral nervous system in early diabetes. In: R.A. Camerini-Davalos and H.S. Cole (Eds.). Vascular and Neurologic Changes in Early Diabetes. Academic Press, New York, NY, pp. 441449.

4 Said, G.. Slama. G. and Selva. J. (1983) Progressive centripetal degeneration of axons in small fiber diabetic polyneuropathy. Brain 106, 791-807.

5 Dyck, P.J., Lais. A., Karnes, J.L., O'Brien, P. and Rizza, R. (1986) Fiber loss in primary and multifocal sural nerves in diabetic polyneuropathy. Ann. Neurol. 19, 425-439. 
6 Dyck, P.J., Karnes, J.L., O’Brien, P., Okazaki, H., Lais, A and Engelstad, J. (1986) The spatial distribution of fiber loss in diabetic polyneuropathy suggests ischemia. Ann. Neurol. 19. 440-449.

7 Johnson, P.C., Doll, S.C. and Cromey, D.W. (1986) Pathogenesis of diabetic neuropathy. Ann. Neurol. 19,450-457.

8 Dyck. P.J., Karnes, J., Lais, A., Lofgren, E.P. and Stevens, J.C. (1984) Pathologic alterations of the peripheral nervous system of humans. In: P.J. Dyck, P.K. Thomas, E.H. Lambert and R. Bunge (Eds.), W.B. Saunders, Philadelphia, PA. pp. 760-870.

9 Sima, A.A.F., Nathaniel, V., Bril, V., McEwen, T.A.J. and Greene, D.A. (1988) Histopathological heterogeneity of neuropathy in insulin-dependent and non-insulin-dependent diabetes, and demonstration of axo-glial dysjunction in human diabetic neuropathy. J. Clin. Invest. 81, 349-364.

10 Greene, D.A., Chakrabarti, S., Lattimer, S.A. and Sima, A.A.F. (1987) Role of sorbitol accumulation and myo-inositol depletion in paranodal swelling of large myelinated nerve fibers in the insulin deficient spontaneously diabetic Bio-breeding rat: reversal by insulin replacement, an aldose reductase inhibitor and myo-inositol. J. Clin. Invest. 79 1479-1485.

11 Brismar, T. and Sima, A.A.F. (1981) Changes in nodal function in nerve fibers of the spontaneously diabetic BB-Wistar rat. Potential clamp analysis. Acta Physiol. Scand. 113,499506.

12 Sima. A.A.F. and Brismar, T. (1985) Reversible diabetic nerve dysfunction: structural correlates to electrophysiological abnormalities. Ann. Neurol. 18, 21-29.

13 Brismar, T., Sima, A.A.F. and Greene, D.A. (1987) Reversible and irreversible nodal dysfunction in diabetic neuropathy. Ann. Neurol. 21, 504-507.

14 Chakrabarti, S., Sima, A.A.F., Nakajima, S., Yagihashi, S. and Greene, D.A. (1987) Aldose reductase in the BB-rat: isolation, immunological identification and localization in the retinal and peripheral nerve. Diabetologia 30, 244251.

15 Sima. A.A.F. (1980) Peripheral neuropathy in the spontaneously diabetic BB-Wistar rat. Acta Neuropathol. 51, 223232.

16 Sima. A.A.F., Bouchier, M. and Christensen, H. (1983) Axonal atrophy in sensory nerves of the diabetic BB-Wistar rat. A possible early correlate of human diabetic neuropathy. Ann. Neurol, 13, 264-272.

17 Sima, A.A.F. (1985) Annotation: Can the BB-rat help to unravel diabetic neuropathy? Neuropathol. Appl. Neurobiol. 11. 253-264.

18 Sima, A.A.F., Lattimer, S.A., Yagihashi, S. and Greene, D.A. (1986) Axo-glial dysfunction. A novel structural lesion that accounts for poorly reversible slowing of nerve conduction in the spontaneously diabetic Bio-breeding rat. J. Clin. Invest. 77, 474-484.

19 Sima, A.A.F. and Thibert, P. (1982) Proximal motor neuropathy in the BB-Wistar rat. Diabetes 31, 784-788.

20 Sima, A.A.F, and Yagihashi, S. (1986) Distal central-periph- eral axonopathy in the spontaneously diabetic BB-Wistar rat: an ultrastructural and morphometric study. Diabetes Res. Clin. Pract. I, 289-298.

21 Greene, D.A., Yagihashi, S., Lattimer, S.A. and Sima. A.A.F. (1984) Nerve $\mathrm{Na}^{+}-\mathrm{K}^{+}-\mathrm{ATPa}$ ase, conduction and myo-inositol in the insulin deficient BB-rat. Am. J. Physiol. 247. E534-E539.

22 Greene, D.A. Lattimer, S.A. and Sima, A.A.F. (1987) Sorbitol, phosphoinositides and the sodium-potassium ATPase in the pathogenesis of diabetic complications. N. Engl. J. Med. 316, 599-606.

23 Sima. A.A.F., Brismar. T. and Yagihashi. S. (1987) Neuropathies encountered in the spontaneously diabetic BB Wistar rat. In: P. Dyck. P.K. Thomas, A.K. Asbury. A.I. Winegrad and D. Porte Jr. (Eds.), Diabetic Neuropathy. W.B. Saunders, Philadelphia, PA, pp. 253-259.

24 Westfall, S.G., Felten, D.L., Mandelbaum, J.A., Moore, S.A. and Peterson, R.G. (1983) Degenerative neuropathy in insulin-treated diabetic rats. J. Neurol. Sci. 61. 93-107.

25 Mandelbaum. J.A., Felten, D.L., Westfall, S.G., Newlin. G.E. and Peterson, R.G. (1983) Neuropathic changes associatcd with insulin treatment of diabetic rats: electronmiscroscopic and morphometric analysis. Brain Res. Bull. 10, 377 384.

26 Marliss, E.B., Sima, A.A.F. and Nakhooda, A.F. (1981) Spontaneous diabetes in the 'BB' Wistar rat. In: J.M. Martin et al. (Eds.), Etiology and Pathogenesis of Insulin-Dependent Diabetes Mellitus. Raven Press, New York. NY. pp. 251-274.

27 Marliss, E.B., Nakhooda, A.F., Poussier. P. and Sima, A.A.F. (1982) The diabetic syndrome of the BB Wistar rat. Possible relevance to type $\mathbf{I}$ (insulin-dependent) diabetes in man. Diabetologia 22, 225-232.

28 Sima, A.A.F. and Hay, K. (1981) Functional aspects and pathogenetic considerations of the neuropathy in the spontaneously diabetic BB-Wistar rat. Neuropathol. Appl. Neurobiol. 7, 341-350.

29 Dyck. P.J.. Karnes, J., Lais, A., Lofgren, E.P. and Stevens, J.C. (1984) Pathologic alterations of the peripheal nervous system of humans. In: P.J. Dyck, P.K. Thomas, E.H. Lambert and R. Bunge (Eds.), Peripheral Neuropathy. W.B. Saunders, Philadelphia, PA, pp. 760-870.

30 Mendell, I.R., Sahenk, Z., Wormolts, J.R.. Marshall, J.K. and Thibert, P. (1981) The spontaneously diabetic Wistar rat. Morphologic and physiologic studies of peripheral nerve. J. Neurol. Sci. 52, 103-115.

31 Sidenius. P. and Jakobsen. J. (1983) Peripheral neuropathy in rats induced by insulin treatment. Diabetes 32, 383-386.

32 Jakobsen, J. and Sidenius. P. (1987) Hypoglycemic neuropathy. In: P. Dyck, P.K. Thomas, A.K. Asbury, A.I. Winegrad and D. Porte Jr. (Eds.), Diabetic Neuropathy. W.B. Saunders, Philadelphia, PA, pp. 94-99.

33 Moersch, F.P. and Kernahan, J.W. (1938) Hypoglycemia: neurologic and neuropathologic studies. Arch. Neurol. Psychiatry $39,242-257$. 
34 Tom, M.I. and Richardson, J.C. (1951) Hypoglycemia from islet cell tumor of pancreas with amyotrophy and cerebrospinal nerve cell damage. J. Neuropathol. Exp. Neurol. 10, 5766.

35 Rosner, L. and Elstad, R. (1964) The neuropathy of hypoglycemia. Neurology 14, 1-6.

36 Danta, G. (1969) Hypoglycemic peripheral neuropathy. Arch. Neurol. 21, 121-132.

37 Harrison. M.J.G. (1976) Muscle wasting after prolonged hy- poglycemic coma: case report with electrophysiological data. J. Neurol. Neurosurg. Psychiatry 39, 465-470.

38 Jaspan, J.B., Wollman, R.L., Bernstein. L. and Rubinstein. A.H. (1982) Hypoglycemic peripheral neuropathy in association with insulinoma: implication of glucopenia rather than hyperinsulinemia. Case report and literature review. Medicine 61, 33-44.

39 Editorial (1982) Hypoglycemic peripheral neuropathy. Lancet $2,1447-1448$. 